Article

\title{
Modeling the Spatial Dimensions of Warehouse Rent Determinants: A Case Study of Seoul Metropolitan Area, South Korea
}

\author{
Hyunwoo Lim * and Minyoung Park \\ Asia Pacific School of Logistics, INHA University, Incheon 22212, Korea; mypark@inha.ac.kr \\ * Correspondence: hwlim@inha.ac.kr
}

Received: 15 October 2019; Accepted: 26 December 2019; Published: 28 December 2019

\begin{abstract}
The spatial mismatch between warehouse locations and urban freight demand mainly driven by logistics sprawl can have negative environmental impacts, due to the increase in average trucking distances. This study investigated the spatial dimension of warehouse rent determinants identifying the regional specifics of supply and demand of warehouse facilities and services. Based on the case of the Seoul Metropolitan Area in South Korea, spatial autoregressive regression (SAR) and mixed geographically weighted regression (MGWR) models were developed to explain the spatial stationary and non-stationary relationship between warehouse rent and the explanatory variables, including the transactional characteristics of the rental contracts, physical characteristics of the buildings, location factors, and various warehousing services. The MGWR results identified the distance to the nearest highway interchange, repackaging service, and built-in ramps as globally fixed variables and contract floor space, total building floor space, building age, and land price as locally varying variables. The results of this study allowed us to provide meaningful insights into the sustainable development of urban logistics facilities through a better understanding of the interaction between logistics activities, transportation infrastructure, and land use.
\end{abstract}

Keywords: Warehouse rent; sustainable urban logistics; hedonic price modeling; spatial autoregressive regression; mixed geographically weighted regression

\section{Introduction}

Warehouses match product availability to customer orders by storing inventory over time, acting as a buffer between supply and demand. As one of the major industrial properties requiring a substantial amount of land, warehouses affect land use, freight transportation, and regional economies [1-3]. Locations of warehouses have moved from inner urban areas to suburban and exurban areas (often referred to as "logistics sprawl") in many countries over the past few decades, due to high land price and lack of commercial and industrial land for large warehouses in urban areas [3,4]. However, freight activities in inner urban areas are increasing - mainly driven by the growth of online sales and the increasing need for quick order fulfillment $[3,5]$. Such mismatch between logistics land use and freight activities can have negative environmental impacts, such as an increase in traffic congestion and greenhouse gas emissions, due to an increase in average trucking distances [4].

To provide effective policy measures to mitigate the negative environmental impacts of logistic sprawl, it is necessary to understand the regional specifics of the supply and demand relationship of warehouses in the corresponding metropolitan area [6]. Many studies have provided descriptive analyses of logistics sprawl in a number of large metropolitan areas in Europe, North America, Japan, and China [4,6-10]. For instance, Sakai et al. [6,8] analyzed the change of spatial distribution of logistics facilities between 1980 and 2003 based on the Tokyo Metropolitan Freight Survey (TMFS) data and 
stressed the importance of local policies to assure the adequate supply of industrial land for logistics facilities in urban areas. However, the studies mentioned above did not address the regional specific needs of warehousing operations and facility requirements and their provisions which may vary by location across the metropolitan areas.

Alternatively, analyzing the spatial distribution of warehouse rent and its determinants can provide an improved understanding of the regional specifics of supply and demand of warehouses in the metropolitan areas if the necessary warehouse rent data can be obtained. Warehousing can take place either through private ownership or renting storage space from a third-party warehouse. According to the 2019 Third-Party Logistics Study [11], 69\% of shippers outsource warehousing activities implying that the majority of the companies rent storage spaces from third-party warehouses rather than having their own private warehouses. Throughout this paper, we will refer to a "rental storage unit" as part of the warehouse storage space available for rent. Readers should note that a single warehouse building can have multiple rental storage units rented to multiple customers. One of the advantages of renting warehouse space is that it does not require any capital investment for the renters and provides better flexibility if they need to move their storage location in response to the changes in market conditions [12].

Warehouse rent represents the value of the rental storage unit in terms of its physical, locational, and lease characteristics $[13,14]$. The warehouse rental price is determined at an equilibrium in which the storage space provided matches the customer's need and ability to rent the storage space. Determinants of warehouse rent indicate the specific needs of warehousing activities required by the customers and the rental price reflects the availability of warehouses capable of satisfying such needs. Following the literature on real estate and urban studies [15-17], we can claim that analyzing the spatial variation of warehouse rent and its determinants can contribute to improved understanding of the interaction between storage demand, logistics activities, transportation infrastructure, and land availability. In practice, a better understanding of the mechanism of warehouse rent determinations also allows warehouse landlords to appropriately price their properties according to the market condition and warehouse renters to reduce search costs [18].

Past studies on warehouse rent are rare, with the exception of a few studies on industrial property rent or value [19-21]. Most of these studies relied on ordinary least square (OLS) regression models to identify rental price determinants under the hedonic price modeling framework. However, storage units closer to one another are more likely to have similar rent values similar to other types of real estate property, a phenomenon known as spatial autocorrelation or spatial dependency [22]. The presence of spatial autocorrelation in warehouse rent is problematic because it violates the assumption of independent observations in the OLS regression. Therefore, applying OLS regression to warehouse rent data with significant spatial autocorrelation results in the biased and unreliable estimation of regression coefficients [23]. Moreover, the conventional OLS regression models assume stationary relationships between the rental price and its explanatory variables over the entire study area [24]. However, such a homogeneous warehouse rental market may not exist. Instead, there may be local variations in the relationship between the rental price and its explanatory variables. So far, we have not yet come across any studies on warehouse rent determinants considering both spatial dependence and heterogeneity.

To fill in the gap in the literature, the present study intends to examine the spatial dimensions of warehouse rent determinants considering spatial dependence and spatial heterogeneity. We propose hedonic pricing models that can explain warehouse rent through explanatory variables, including the transactional characteristics of the rental contracts, physical characteristics of the buildings, location factors, and various warehousing services. Based on the case of the Seoul Metropolitan Area (SMA) in South Korea, we used spatial autoregressive models to explicitly reflect the spatial autocorrelation in the warehouse rent data. Furthermore, we examined the spatial stationary and non-stationary relationship between warehouse rent and its determinants by implementing a mixed geographically weighted regression (MGWR) model. MGWR allows certain explanatory variables to be globally 
fixed, while others vary locally. Through the improved understanding of the spatial dependency and heterogeneity of the warehouse rent determinants, we expect to provide meaningful insights for the sustainable development of logistics facilities by reducing the spatial mismatch between supply and demand of warehousing space in the metropolitan areas.

\section{Literature Review}

Rent is used as part of the many important criteria for deciding whether a firm should own a property or rent and at the same time, where to locate it [14]. The role of rent and its determinants have been the research subjects in urban and transportation studies for many decades. The earliest attempt was made by von Thünen in 1826 explaining the agricultural land rent by the distance to markets in his book The Isolated State. This work served as a foundation for establishing a theory about the relationship between land use and rents in urban areas [16]. For instance, Alonso [25] adopted this concept in establishing a theory about the trade-off between the cost of transportation to the Central Business District (CBD) and rental price in urban areas using bid-rent functions.

Hedonic price modeling has been widely used to assess property value and to estimate the demand for specific attributes of properties and their neighborhoods [21]. Hedonic price theory argues that the utility of the good is created by its individual characteristics rather than by the good itself [26]. Real estate properties are usually considered as heterogeneous goods because each property is valued by its bundle of inseparable characteristics [27]. Therefore, a consumer implicitly chooses a set of different characteristics by selecting a specific property [28]. A hedonic price function explains the relationship between the real estate price and the property attributes, including physical, locational, transactional, and neighborhood-related characteristics [14,27]. Usually, the hedonic price function is estimated by multiple regression analyses using a semi-log or log-log specification.

Housing has been the most dominant research subject among all types of real estate properties in the urban and transportation literature $[17,24,29,30]$. Studies exclusively on warehouse rent were rare in the past, but several studies on industrial properties do exist. For instance, Buttimer et al. [19] presented an empirical analysis of industrial warehouse rent determinants based on the case of the Dallas/Fort Worth area in the United States. They identified the number of loading docks and the annual change in net employment as positive determinants. On the contrary, they identified the building age, the ceiling height, percentage of the office space, and the presence of the sprinkler system as the negative determinants. Beekmans et al. [21] used the OLS regression model to estimate the property value of industrial sites in the Netherland based on physical attributes of the buildings, regional economies, and overall economic trends.

However, using conventional OLS regression in hedonic price analysis has two major challenges: Spatial autocorrelation and spatial heterogeneity. Spatial autocorrelation refers to the phenomenon such that features that are closer together tend to have more similar values caused by similar socioeconomic and environmental characteristics in the neighborhood [23]. When spatial autocorrelation is significantly present in the data, the traditional OLS estimator becomes inefficient and unreliable [22]. To explicitly account for the effect of the spatial autocorrelation, spatial autoregressive models proposed by Anselin [23] can be adopted to hedonic price analysis. For instance, Clark and Pennington-Cross [14] analyzed the relationship between industrial property rents and its determinants in the Chicago metropolitan area using spatial error model (SEM) where spatial autocorrelation is reflected in the error term. For significant rent determinants, they identified the physical characteristics of the property, lease term structure, and local demographic attributes of the neighborhood.

Spatial heterogeneity implies spatial non-stationarity or spatial variation in the relationship between the rental price and its determinants. Different types of models to consider spatial heterogeneity in hedonic price modeling include a fixed-effect model, random effect model, multilevel regression, spatial expansion model, and geographically weighted regression (GWR) [27]. GWR has substantial advantages over other mentioned models: (i) It does not rely on the exogenous assumption of pre-defined spatial units; and (ii) it models locally varying price functions explicitly considering 
both spatial autocorrelation and spatial heterogeneity. Wu et al. [29] analyzed the housing price influence factors and their spatial variability in Wuhan, China using the hedonic linear regression model, the GWR, and the artificial neural network (ANN) model. They identified four major influence factors on housing price with significant spatial variabilities: Distance to the inner ring, distance to hospitals, bus density, and distance to subway stations. Lan et al. [24] applied the MGWR and the geographical detector (GD) to analyze the spatial effect of accessibility to public service facilities on housing prices based on the case of Xi'an, China.

As the integration of clustering and multivariate regression analysis, Lim et al. [31] introduced an application of spatial profile regression for delineating warehouse rental submarkets. This method enabled them to group profiles of rental storage units into a number of submarkets based on the association between rental rates and its determinants, while considering spatial autocorrelation and potential multicollinearity in the data set. However, the main limitation of spatial profile regression is that it cannot be used to predict warehouse rent or estimate the marginal effect of the explanatory variables, unlike other types of regression models.

The present study contributes to the literature by examining the spatial stationary and non-stationary relationship between warehouse rent and its determinants. This can uncover the regional specifics of supply and demand of warehousing activities in the metropolitan areas providing policy implications for sustainable development of logistics facilities in the metropolitan areas.

\section{Data and Models}

\subsection{Data Description}

The study area of this research is SMA which includes Seoul, Incheon, and Gyeonggi Provinces in South Korea. Because warehouse rent transaction records are not publicly available in South Korea, we used the data originally collected by Yang [32] who conducted surveys and interviews in 2015 to rental warehouse clients, including manufacturers, retailers, and third-party logistics companies. The original data include 153 rental records for 120 warehouses out of the 931 rental warehouses in the SMA registered to the Ministry of Land, Infrastructure, and Transport (MOLIT) in 2015. The scope of the present study is focused on the 122 rental records for the regular (dry) warehouses. The analysis for the remaining 31 records for the cold/refrigerated warehouse is left for future study as they have distinctively different market characteristics. The data used in the present study include specifications of the lease contract, physical characteristics of the building, locational attributes, and additional warehousing services as listed in Table 1. Readers should refer to Lim et al. [31] for more details on the data, including the descriptive statistics of the variables.

Table 1. List of variables by category.

\begin{tabular}{|c|c|c|c|}
\hline $\begin{array}{c}\text { Lease Contract Related } \\
\text { Variables }\end{array}$ & Physical Variables & Locational Variables & $\begin{array}{l}\text { Service-related Variables } \\
\text { (Dummy Variables) }\end{array}$ \\
\hline $\begin{array}{ll}\text { - } & \text { Warehouse rent } \\
\text { - } & \text { Contract floor space } \\
\text { - } & \text { Lease length }\end{array}$ & $\begin{array}{ll} & \text { Building age } \\
- & \text { Total floor space } \\
- & \text { Floor size of the } \\
& \text { rented space } \\
\text { - } & \text { Built-in ramps } \\
& \text { (dummy variable) }\end{array}$ & $\begin{array}{ll}\text { - } & \text { Land price } \\
\text { Distance to the nearest } \\
\text { highway interchange }\end{array}$ & $\begin{array}{ll}\text { - } & \text { Automation } \\
\text { - } & \text { High-rack } \\
\text { - } & \text { Retail-ready service } \\
\text { - } & \text { Repackaging } \\
\text { - } & \text { Warehouse } \\
& \text { Management System } \\
\text { - } & \text { Bonded } \\
\text { - } & \text { Night operation } \\
\text { - } & \text { Transportation services }\end{array}$ \\
\hline
\end{tabular}


Figure 1 illustrates the spatial distribution of monthly warehouse rent in Korean Won (KRW) per square meter for the 122 rental storage units in the SMA. Because a single warehouse building can have multiple rental storage units, different rent values can be reported in the same warehouse location. Among the 122 rental storage units, 60 of them are located near Icheon and Yongin cities in the southeastern Gyeonggi Province with high variability of rental prices. Warehouse rent is generally higher for the warehouse more closely located to the center of Seoul, mainly because of the higher land price. Warehouse rent is highest in Songpa-gu of Seoul followed by the Gimpo City of Gyeonggi Province, due to easy access to densely populated inner urban areas in Seoul.

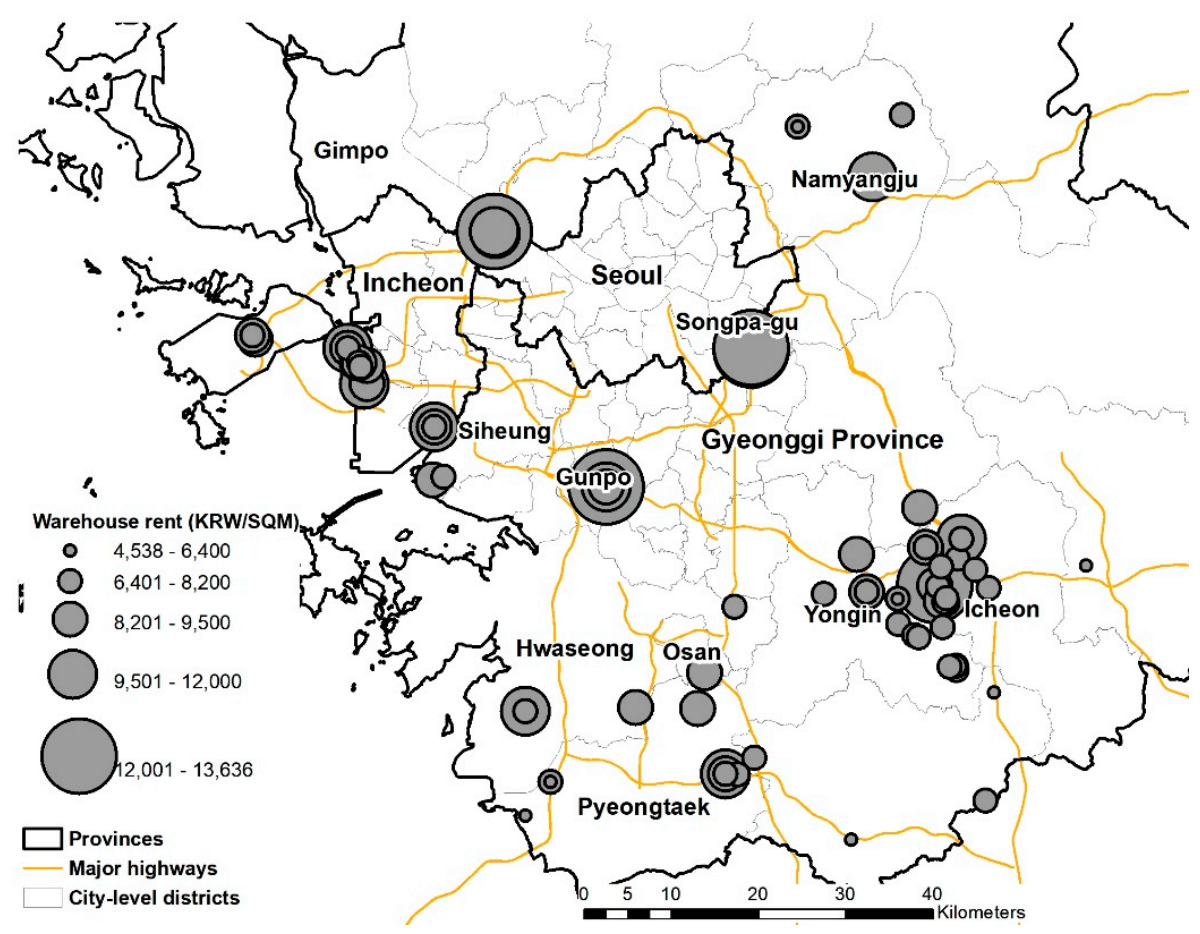

Figure 1. Spatial distribution of warehouse rents in the Seoul Metropolitan Area (SMA).

\subsection{Model Specification}

Like any other real estate property, a rental storage unit is valued by its bundle of inseparable warehousing characteristics rather than by the storage unit itself. Thus, a warehouse user implicitly chooses a set of different warehouse attributes and services by renting a storage unit from the warehouse. Previous studies on industrial property rent used characteristics related to physical property, lease structure, market condition, and accessibility to transportation infrastructures [14,19]. Under this framework of hedonic price modeling, the warehouse rent ${ }^{\circledR}$ can be expressed as the following function of transactional $(T)$, physical $(P)$, locational $(L)$, and service $(S)$ related characteristics of the warehouse, as well as the error term $\varepsilon$ :

$$
R=f(T, P, L, S)+\varepsilon .
$$

The warehouse rent determination function in equation (1) can be formulated in various model specifications, including level-level (linear), log-level, level-log, and log-log specifications. The level-level specification would be the most appealing because the estimated regression coefficient can be interpreted as the marginal price of the corresponding warehouse determinants. However, the log-log model resulted in a better fit than linear or semi-logarithmic specifications, because of the nonlinear relationship between the dependent and independent variables. Therefore, we decided to adopt a log-log model with dummy variable specifications to model the warehouse rent determinant function. In addition to the conventional OLS regression model, this study implements spatial regression models to incorporate spatial autocorrelation in the data set. To identify the warehouse rent 
determinants, the log of monthly warehouse rent $\left(\mathrm{KRW} / \mathrm{m}^{2}\right)$ is regressed on the various log-transformed explanatory variables listed in Table 1 . Considering the spatial autocorrelation in the warehouse rent, spatial autoregressive models are implemented, as well as the conventional OLS regression model. The MGWR model is also implemented to identify the local variation in the explanatory variables.

\subsection{Spatial Autoregression}

Two types of spatial autoregressive methods are implemented to incorporate spatial autocorrelation in warehouse rent determinant models: The spatial lag and spatial error models [23].

$$
y=\rho \mathbf{W} y+\beta \mathbf{X}+\varepsilon,
$$

where $y$ is a vector of the observed log-transformed warehouse rent, $\mathbf{X}$ is a matrix, including all the explanatory variables included in the model, $\beta$ is a vector of regression coefficients, including the constant, $\mathbf{W}$ is a row standardized spatial weight matrix that summarizes the spatial relationship among storage units, $\rho$ is the spatial lag coefficient; and $\varepsilon$ is an independent and identically distributed (iid) error term. The term $\mathbf{W} y$ represents the influence of neighboring warehouse rent on the focal warehouse rent.

Conversely, the spatial error model reflects spatial autocorrelation by incorporating the spatial weight matrix $\mathbf{W}$ in the error term formulated as follows:

$$
\begin{gathered}
y=\beta \mathbf{X}+\varepsilon, \\
\varepsilon=\lambda \mathbf{W} \varepsilon+\mu,
\end{gathered}
$$

where $\mu$ is an iid error term and $\lambda$ is the coefficient of the error.

Because of the spatial autoregressive terms $\rho \mathbf{W} y$ and $\lambda \mathbf{W} \varepsilon$, the maximum likelihood estimator is used to estimate regression coefficients instead of the OLS estimator [23]. Therefore, the Akaike information criterion (AIC), a likelihood-based goodness-of-fit measure, was used to evaluate the model's goodness-of-fit for the data instead of the conventional OLS R-square. The spatial weight matrix $\mathbf{W}$ is row standardized and is defined as distance-band weights where observations $i$ and $j$ are considered neighbors when $j$ falls within a critical distance from $i$. More specifically, $w_{i j}=1$ if $d_{i j} \leq \delta$ and $w_{i j}=0$ otherwise, where $\delta$ is a critical distance cutoff. In our sample dataset, $15 \mathrm{~km}$ is the smallest distance that can ensure that each storage location has at least one neighbor. In this study, we constructed spatial weight matrices with a few different critical distances, $15 \mathrm{~km}, 20 \mathrm{~km}$, and $25 \mathrm{~km}$, and chose the one with the best performance.

\subsection{Mixed Geographically Weighted Regression}

To better understand the spatial dynamics of warehouse rent determinants at a local level, geographically weighted regression (GWR) can be used to endogenize spatial dependence relationships by estimating a regression equation for every observation in the data [33,34]. Unlike OLS or spatial autoregressive models that produce a single set of parameter estimates for the entire study region, GWR allows regression coefficients to vary over space. A GWR model can be represented as [33]:

$$
y_{i}=\sum_{k} \beta_{k}\left(u_{i}, v_{i}\right) x_{i k}+\varepsilon_{i}
$$

where $y_{i}$ is the dependent variable at location $i, x_{i k}$ is the $k$ th explanatory variable at location $i,\left(u_{i}, v_{i}\right)$ denotes the coordinates of location $i$, and $\beta_{k}\left(u_{i}, v_{i}\right)$ is the regression coefficient corresponding to $x_{i k}$.

However, dummy variables or categorical variables are often suggested not be included as explanatory variables in a GWR model because they can cause local multicollinearity that can hamper any meaningful interpretation of local GWR estimates [35]. This problem can occur when there is a local area with more than one dummy variable having the same value. This is problematic in this 
study because the warehouse service-related variables in the dataset are all dummy variables. As an alternative to the conventional GWR, Brunsdon et al. [36] proposed a mixed GWR (MGWR) model in which some regression coefficients of the explanatory variables are fixed, while others vary spatially. We refer to explanatory variables with fixed and locally varying regression coefficients as global and local variables, respectively. MGWR can be specified as in Brunsdon et al. [36]:

$$
y_{i}=\sum_{k=1}^{q} \beta_{k} x_{i k}+\sum_{k=q+1}^{p} \beta_{k}\left(u_{i}, v_{i}\right) x_{i k}+\varepsilon_{i}
$$

where the first $q$ explanatory variables are global, and the remaining $p-q$ variables are local. The regression intercept can be constant or spatially varying by taking $x_{i 1}=1$ or $x_{i, q+1}=1$. For technical details of the MGWR coefficient estimation approach, readers should refer to Fotheringham et al. [34].

How an explanatory variable is determined to be global or local is an important issue. We determined all the warehouse service-related variables (dummy variables) to be global to avoid potential local multicollinearities. The rest of the explanatory variables are determined to be global or local by the geographical variability test proposed by Nakaya et al. [37]. To test the geographical variability of the $k$ th varying coefficient, a comparison is made between two models: (i) A base model in which only the dummy variables are kept global and the rest are set as local and ii) a switch model in which the $k$ th variable in addition to the dummy variables are kept global, and rest of the variables are set as local. The performance of the two models is evaluated by the AIC difference as follows:

$$
\text { AIC difference }=\text { AIC of the switch model }- \text { AIC of the base model. }
$$

If the switch model performs better than the base model with a smaller AIC, the difference of AIC of the criterion will have a negative value implying that the $k$ th variable should remain local. This test is repeated for each potential local variable.

The MGWR estimates regression coefficients at each sample location in the dataset by incorporating the dependent and explanatory variables of neighboring locations within the bandwidth from the target location. The shape and size of the bandwidth are dependent on the user-specified parameters, including kernel type, bandwidth method, distance, and the number of neighbors. When estimating the regression coefficient for a sample location in the MGWR model, neighboring locations near the target location are assigned with larger weights. The kernel function for the geographic weight is defined as an adaptive bi-square function as follows:

$$
w_{j}\left(u_{i}, v_{i}\right)=\left\{\begin{array}{ll}
{\left[1-\left(d_{i j} / h_{i}\right)^{2}\right]^{2}} & \text { if } d_{i j}<h_{i} \\
0 & \text { otherwise }
\end{array},\right.
$$

where $w_{j}\left(u_{i}, v_{i}\right)$ and $d_{i j}$ are kernel functions and the distance between sample location $i$ and its neighboring location $j$ and $h_{i}$ is the bandwidth determined by the $N$ th nearest neighbor's distance from $i$. The adaptive kernel function allows the incorporation of the same number $(N)$ of neighbors around each sample location $i$ even if the data points are not evenly distributed across the study area. Thus, a smaller bandwidth $\left(h_{i}\right)$ is assigned for sample location $i$ if the surrounding data points are more densely distributed. On the contrary, the size of the bandwidth becomes larger if the neighboring data points are more sparsely distributed around the sample location $i$. The optimal bandwidth for each sample location is determined by minimizing the AIC.

The model performances in estimating warehouse rent are compared between the OLS, spatial autoregressive, and MGWR models. Because the conventional goodness-of-fit criterion, the adjusted R-square, is not applicable in spatial autoregressive models, the AIC is used as a measure of goodness-of-fit performance. In general, model prediction accuracy can be assessed using the root mean squared error (RMSE) measure. However, the data used in the present study do not have 
enough sample records to divide between training and testing data set. Therefore, prediction accuracy assessment for each model is not performed in the present study.

\section{Results}

\subsection{The OLS and Spatial Autoregressive Models}

The computation for estimating the OLS and two spatial autoregressive models were conducted in GeoDa 1.12.01. As a baseline for modeling warehouse rent determinant, we constructed an OLS regression model, including all the explanatory variables in the dataset with log-log and dummy variable specifications (Table 2). Among all the explanatory variables, the statistically significant coefficients at the 5\% significance level were: Total building floor space, land price, distance to highway interchange, repackaging, warehouse management system (WMS), and built-in ramps. The variance inflation factors (VIF) of two dummy variables, repackaging, and WMS, were relatively high, indicating possible multicollinearities between them. This suggests that one of the two variables should be excluded from the regression model. Bruesch-Pagan (BP) statistic indicated significant heteroskedasticity in the relationship between the dependent and the explanatory variables. Moran's I statistic confirmed that spatial autocorrelation is present in the regression residuals.

Table 2. Ordinary least square (OLS) regression results, including all the explanatory variables.

\begin{tabular}{|c|c|c|c|c|c|}
\hline \multicolumn{6}{|c|}{$\begin{array}{l}\text { Dependent Variable: } \log (\text { Warehouse Rent }) \\
\text { Adj. R-sq. }=0.459 \\
\text { Diagnostic for Heteroskedasticity } \\
\text { Breusch-Pagan }(B P) \text { test value }=31.730(p \text {-value }=0.007) \\
\text { Spatial Autocorrelation of Residuals } \\
\text { Moran's I }=0.231(p \text {-value }=0.000)\end{array}$} \\
\hline Variable & Description & Coef. & t-stat & Prob. & VIF \\
\hline Intercept & Intercept & 9.690 & 30.479 & 0.000 & \\
\hline LNCTRFS & Log(contract floor space) & 0.025 & 1.790 & 0.076 & 2.009 \\
\hline LNFLSP *** & Log(total building floor space) & -0.057 & -2.770 & 0.006 & 1.828 \\
\hline LNAGE & Log(building age) & -0.011 & -0.741 & 0.459 & 1.709 \\
\hline LNPRICE $^{* * *}$ & Log(land price) & 0.050 & 2.735 & 0.007 & 1.796 \\
\hline LNICKM $^{* *}$ & Log(distance to highway interchange) & -0.037 & -2.515 & 0.013 & 1.473 \\
\hline FOOD & Primarily storing food (dummy) & 0.029 & 0.829 & 0.408 & 1.225 \\
\hline AUTO & Automated warehousing (dummy) & -0.025 & -0.702 & 0.483 & 1.776 \\
\hline HIGH-RACK & High-rack available (dummy) & 0.010 & 0.291 & 0.771 & 1.782 \\
\hline RETAIL & Retail-ready service (dummy) & -0.013 & -0.365 & 0.715 & 2.062 \\
\hline REPACK ** & Repacking service (dummy) & 0.142 & 2.182 & 0.031 & 5.489 \\
\hline NIGHT & Night operation service (dummy) & 0.034 & 0.822 & 0.412 & 2.108 \\
\hline BONDED & Bonded warehouse permit (dummy) & -0.047 & -1.385 & 0.168 & 1.735 \\
\hline TRANSPORT & Transport service (dummy) & -0.067 & -1.539 & 0.126 & 2.330 \\
\hline WMS ** & Warehouse Management System (dummy) & 0.123 & 2.081 & 0.039 & 4.827 \\
\hline RAMP *** & Built-in ramps (dummy) & 0.334 & 3.113 & 0.002 & 1.679 \\
\hline
\end{tabular}

After eliminating statistically insignificant variables through a stepwise regression procedure, the following seven variables were chosen to be included in the OLS and spatial autoregressive regression models: Contract floor space, total building floor space, building age, land price, distance to 
the nearest highway interchange, repackaging service, and built-in ramps. Table 3 summarizes the results of regression coefficient estimates and other statistics.

Table 3. Modeling results for the OLS and spatial autoregressive models.

\begin{tabular}{|c|c|c|c|c|c|c|c|c|c|}
\hline & \multicolumn{3}{|c|}{ OLS Model } & \multicolumn{3}{|c|}{ Spatial Lag Model } & \multicolumn{3}{|c|}{ Spatial Error Model } \\
\hline Adj. R-square & \multicolumn{3}{|c|}{0.455} & \multicolumn{3}{|c|}{-} & \multicolumn{3}{|c|}{-} \\
\hline Log-Likelihood & \multicolumn{3}{|c|}{69.052} & \multicolumn{3}{|c|}{73.266} & \multicolumn{3}{|c|}{70.855} \\
\hline $\begin{array}{l}\text { Diagnostic for } \\
\text { heteroskedasticity }\end{array}$ & \multicolumn{3}{|c|}{$\begin{array}{c}\mathrm{BP}=20.128 \\
(p \text {-value }=0.005)\end{array}$} & \multicolumn{3}{|c|}{$\begin{array}{c}\mathrm{BP}=17.267 \\
(p \text {-value }=0.015)\end{array}$} & \multicolumn{3}{|c|}{$\begin{array}{c}\mathrm{BP}=18.374 \\
(p \text {-value }=0.010)\end{array}$} \\
\hline $\begin{array}{l}\text { Spatial } \\
\text { autocorrelation } \\
\text { of residuals }\end{array}$ & \multicolumn{3}{|c|}{$\begin{array}{c}\text { Moran's I = } 0.385 \\
(p \text {-value }=0.000)\end{array}$} & \multicolumn{3}{|c|}{$\begin{array}{c}\text { Moran's I = 0.176 } \\
(p \text {-value }=0.040)\end{array}$} & \multicolumn{3}{|c|}{$\begin{array}{c}\text { Moran's I }=0.250 \\
(p \text {-value }=0.004)\end{array}$} \\
\hline $\begin{array}{c}\text { Spatial } \\
\text { dependency } \\
\text { test }\end{array}$ & \multicolumn{3}{|c|}{ - } & \multicolumn{3}{|c|}{$\begin{array}{l}\text { Spatial lag dependency test: } \\
\text { Likelihood Ratio }=8.427 \\
(p \text {-value }=0.003)\end{array}$} & \multicolumn{3}{|c|}{$\begin{array}{c}\text { Spatial error dependency test } \\
\text { Likelihood Ratio }=3.605 \\
(p \text {-value }=0.057)\end{array}$} \\
\hline Variable & Coef. & t-stat & Prob. & Coef. & z-value & Prob. & Coef. & z-value & Prob. \\
\hline Intercept & 9.545 & 33.282 & 0.000 & 6.172 & 5.362 & 0.000 & 9.599 & 32.937 & 0.000 \\
\hline LNCTRFS & 0.035 & 2.702 & 0.007 & 0.030 & 2.470 & 0.013 & 0.032 & 2.614 & 0.008 \\
\hline LNFLSPY & -0.051 & -2.562 & 0.011 & -0.045 & -2.444 & 0.014 & -0.047 & -2.462 & 0.013 \\
\hline LNAGE & -0.025 & -1.762 & 0.080 & -0.025 & -1.936 & 0.052 & -0.027 & -1.833 & 0.066 \\
\hline LNPRICE & 0.054 & 3.241 & 0.001 & 0.040 & 2.492 & 0.012 & 0.050 & 2.765 & 0.005 \\
\hline LNICKM & -0.041 & -3.116 & 0.002 & -0.024 & -1.897 & 0.057 & -0.028 & -1.865 & 0.062 \\
\hline REPACK & 0.196 & 6.283 & 0.000 & 0.162 & 5.346 & 0.000 & 0.169 & 5.133 & 0.000 \\
\hline RAMP & 0.269 & 2.723 & 0.007 & 0.192 & 1.975 & 0.048 & 0.271 & 2.359 & 0.0183 \\
\hline$\rho$ & - & - & - & 0.349 & 3.010 & 0.002 & - & - & - \\
\hline$\lambda$ & - & - & - & - & - & - & 0.397 & 2.752 & 0.005 \\
\hline
\end{tabular}

When the explanatory variables in the OLS regression model were reduced to the selected seven variables, the adjusted R-square was slightly reduced from 0.459 to 0.455 , and the multicollinearity was no longer present. However, the spatial autocorrelation in the residuals was still present, as indicated by the Moran's I of 0.385 with a p-value of less than 0.000 . According to the regression coefficients, warehouse rent was positively associated with contracted floor space, land price, repackaging service, and built-in ramps. Because the regression model is specified as a log-log model, regression coefficients of the continuous variables should be interpreted as price elasticities. If the contracted floor space in the lease is increased by $10 \%$, the warehouse rent is expected to increase by $0.35 \%$. Likewise, a $10 \%$ increase in the land price is associated with a $0.54 \%$ increase in warehouse rent. Providing a repackaging service is associated with a $19.6 \%$ increase in warehouse rent. The presence of built-in ramps is expected to increase warehouse rent by $26.9 \%$, which is the largest effect on increasing warehouse rent among all explanatory variables.

By contrast, the warehouse rent was negatively associated with total building floor space, building age, and distance to the nearest highway intersection. This implies that warehouse rent on average is slightly lower for larger warehouses because they can have more vacant storage spaces available for rent. Newer warehouse buildings and proximity to highway interchanges contribute to an increase in warehouse rent.

For the spatial autoregressive models, using the weight matrix with the critical distance of 15 kilometers generated the best result in terms of minimizing the AIC. The usage of spatial autoregressive models was justified by the likelihood ratio (LR) test results for the spatial lag and spatial error dependency. The spatial lag coefficient $\rho$ and spatial error coefficient $\lambda$ were statistically significant 
at the $1 \%$ significance level. This confirmed that significant spatial autocorrelation was present in the warehouse rent and the error terms. The signs of the regression coefficients of the OLS and two spatial autoregressive models were consistent with one another, but the OLS model overestimated most of the coefficients compared with those of the two spatial autoregressive models. Such overestimation can be explained by the spatial autocorrelation among neighboring warehouse rents. Moran's I statistics indicate that spatial autocorrelation in the residuals for the spatial autoregressive models was still present even though their degrees were significantly decreased from that of the OLS regression model. The BP statistics for the OLS and two spatial autoregressive models indicate the presence of heteroskedasticity in the relationship between the dependent and explanatory variables. This motivates the necessity for a local regression model to estimate the warehouse rent.

\subsection{Mixed Geographically Weighted Regression}

The computation of the MGWR was carried out in GWR4.0, and the results are summarized in Table 4. When implementing the MGWR model, all the dummy variables were set to be global to avoid potential local multicollinearities. We performed a geographic variability test to determine whether the rest of the explanatory variables should be set as local or global. As a result, distance to the nearest highway interchange, repackaging service, and built-in ramps were determined to be global, while the other four variables were determined to be local. The negative sign of the difference of criterion values for the abovementioned four variables confirmed significant geographical variability in their regression coefficients.

Table 4. Mixed geographically weighted (MGWR) results.

\begin{tabular}{|c|c|c|c|c|c|c|c|c|}
\hline \multicolumn{9}{|c|}{$\begin{array}{l}\text { Adj. R-square }=0.578 \\
\text { AIC }=-144.759\end{array}$} \\
\hline \multicolumn{9}{|c|}{ Locally Varying Variables } \\
\hline & Mean & S.D. & Min. & $\begin{array}{c}\text { Lower } \\
\text { Quartile }\end{array}$ & Median & $\begin{array}{c}\text { Upper } \\
\text { Quartile }\end{array}$ & Max. & $\begin{array}{c}\text { Geographical } \\
\text { Variability Test } \\
\text { (Difference of } \\
\text { the AIC)* }\end{array}$ \\
\hline Intercept & 9.715 & 0.477 & 8.537 & 9.428 & 9.896 & 9.954 & 10.770 & -410.465 \\
\hline LNCTRFS & 0.031 & 0.039 & -0.030 & 0.008 & 0.030 & 0.039 & 0.162 & -36.126 \\
\hline LNFLSPY & -0.042 & 0.027 & -0.123 & -0.055 & -0.044 & -0.035 & 0.004 & -97.536 \\
\hline LNAGE & -0.034 & 0.032 & -0.134 & -0.049 & -0.018 & -0.011 & -0.002 & -25.044 \\
\hline LNPRICE & 0.044 & 0.037 & -0.030 & 0.027 & 0.029 & 0.051 & 0.147 & -181.745 \\
\hline \multicolumn{9}{|c|}{ Fixed (global) variables } \\
\hline & \multicolumn{2}{|c|}{ Estimate t-stat. } & $\mathrm{p}$-value & & & & & \\
\hline LNICKM & -0.038 & -2.813 & 0.002 & & & & & \\
\hline REPACK & 0.105 & 2.570 & 0.005 & & & & & \\
\hline RAMP & 0.227 & 1.718 & 0.044 & & & & & \\
\hline
\end{tabular}

Table 5 provides a comparison of the modeling assessment for the OLS, two spatial autoregressive, and MGWR models. The AIC statistics indicated that all the spatial regression models (autoregressive and MGWR) fit the data much better than the OLS regression model. Among the three spatial regression models, the MGWR fitted the data best, whereas, the spatial lag model fitted the data slightly better than the spatial error model. In the MGWR model, the RMSE was minimized, and the Moran's I value, indicating spatial autocorrelation in the residuals, was negligible without showing any statistical significance. 
Table 5. Modeling assessment.

\begin{tabular}{ccccc}
\hline & OLS Model & Spatial Lag Model & Spatial Error Model & MGWR \\
\hline Adj. R-square & 0.425 & - & - & 0.578 \\
\hline AIC & -116.416 & -128.533 & -125.711 & -144.759 \\
\hline Spatial autocorrelation & 0.385 & 0.176 & 0.250 & 0.024 \\
of residuals: Moran's I & $(0.000)$ & $(0.040)$ & $(0.004)$ & $(0.717)$ \\
\hline RMSE & 0.012 & 0.012 & 0.013 & 0.009 \\
\hline
\end{tabular}

The MGWR coefficients of the three fixed variables had slightly different values compared with those from the OLS and spatial autoregressive regressions, but their signs are consistent. If the distance from the warehouse to the nearest highway interchange is reduced by $10 \%$, warehouse rent is expected to increase by $0.38 \%$. The provision of a repackaging service and presence of built-in ramps can lead to a $10.5 \%$ and $22.7 \%$ increase in warehouse rent, respectively. Figure 2 through Figure 5 illustrate the spatial distribution of the MGWR coefficients of the four local variables: Contract floor space, total building floor space, building age, and land price. It should be noted that the locally varying regression coefficients were not statistically significant in all locations. The MGWR coefficient maps only show those coefficients that are statistically significant at the $10 \%$ significance level.

As shown in Figure 2, contract floor space is positively correlated with warehouse rent, but the regression coefficients vary greatly over space ranging from 0.0341 to 0.1625 . The regression coefficients are lowest around Icheon located in the southeastern part of Gyeonggi Province where relatively large numbers of warehouses are clustered. By contrast, regression coefficients are highest in Songpa-gu, Seoul and Namyangju, Gyeonggi Province. This implies that renting additional floor space requires higher rent for warehouses located closer to Seoul where large storage spaces for rent are less available compared with other locations in the SMA.

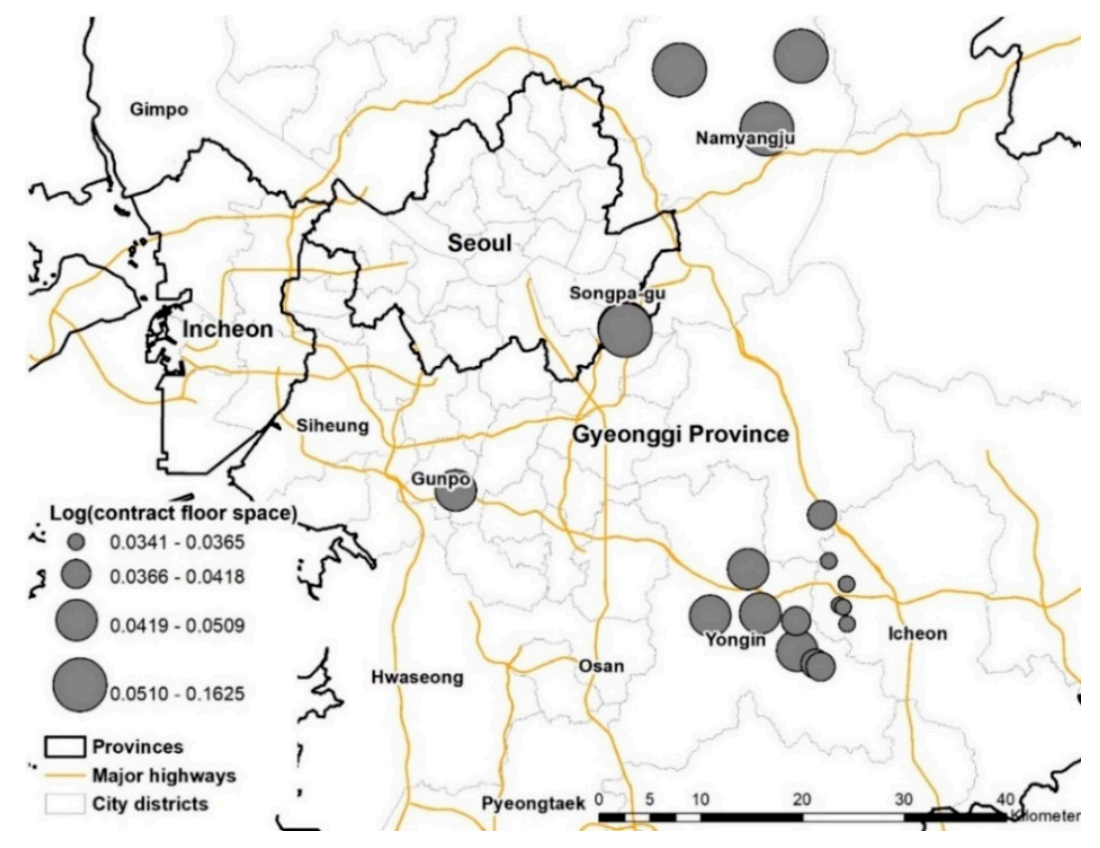

Figure 2. Spatial distribution of MGWR coefficients: Log of contract floor space.

As shown in Figure 3, total floor space is negatively correlated with warehouse rent ranging from -0.1240 to -0.0554 depending on location. The smallest (most negative) coefficients are found in Namyangju located close to the northeastern part of Seoul. This suggests that rent tends to be higher in 
smaller warehouses because storage spaces available for rent are less available in smaller warehouses. This tendency is more severe in Namyangju than in the rest of the warehouse locations in the SMA.

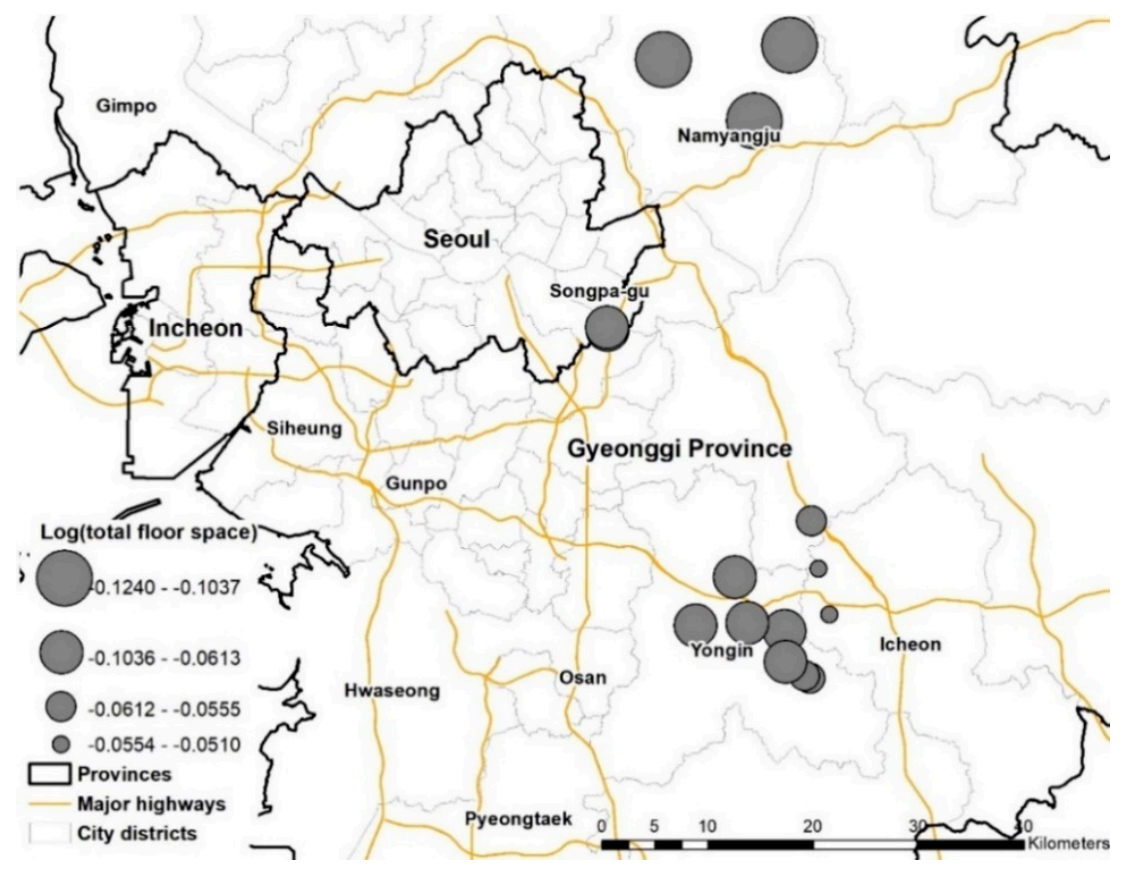

Figure 3. Spatial distribution of MGWR coefficients: Log of total floor space.

The regression coefficients of building age are negative in all locations implying that warehouse rents are expected to be lower in older buildings (Figure 4). The effect of building age on warehouse rent is larger in northern Gyeonggi Province compared to locations in southern Gyeonggi Province. For instance, a 100\% increase in building age is expected to lower warehouse rent by $13 \%$ in Namyangju. However, the same percentage increase in building age is expected to lower warehouse rent by only $5.2 \%$ in Pyeongtaek. This indicates that warehouse rent is more sensitive to building age in Namyangju than the rest of the areas in the SMA.

As illustrated in Figure 5, the MGWR coefficients of land prices range from 0.0628 to 0.1480 . Larger coefficients are mostly located in southwestern Gyeonggi Province near industrial complexes in Pyeongtaek where manufacturing facilities are clustered near the Pyeongtaek Port. The average land price in the Pyeongtaek area was around $294,800 \mathrm{KWR} / \mathrm{m}^{2}$, which was much lower than the SMA wide average land price of $438,290 \mathrm{KWR} / \mathrm{m}^{2}$. However, the effect of the marginal increase in land price on warehouse rent is relatively high in Pyeongtaek. This can be explained by its locational advantages for warehouses handling industrial products for manufacturing companies: Proximity to the seaport, industrial complex, and the national expressway along the west coast. This implies that manufacturing companies are willing to pay extra rent for warehouse space with locational advantages, while attempting to reduce storage costs. 


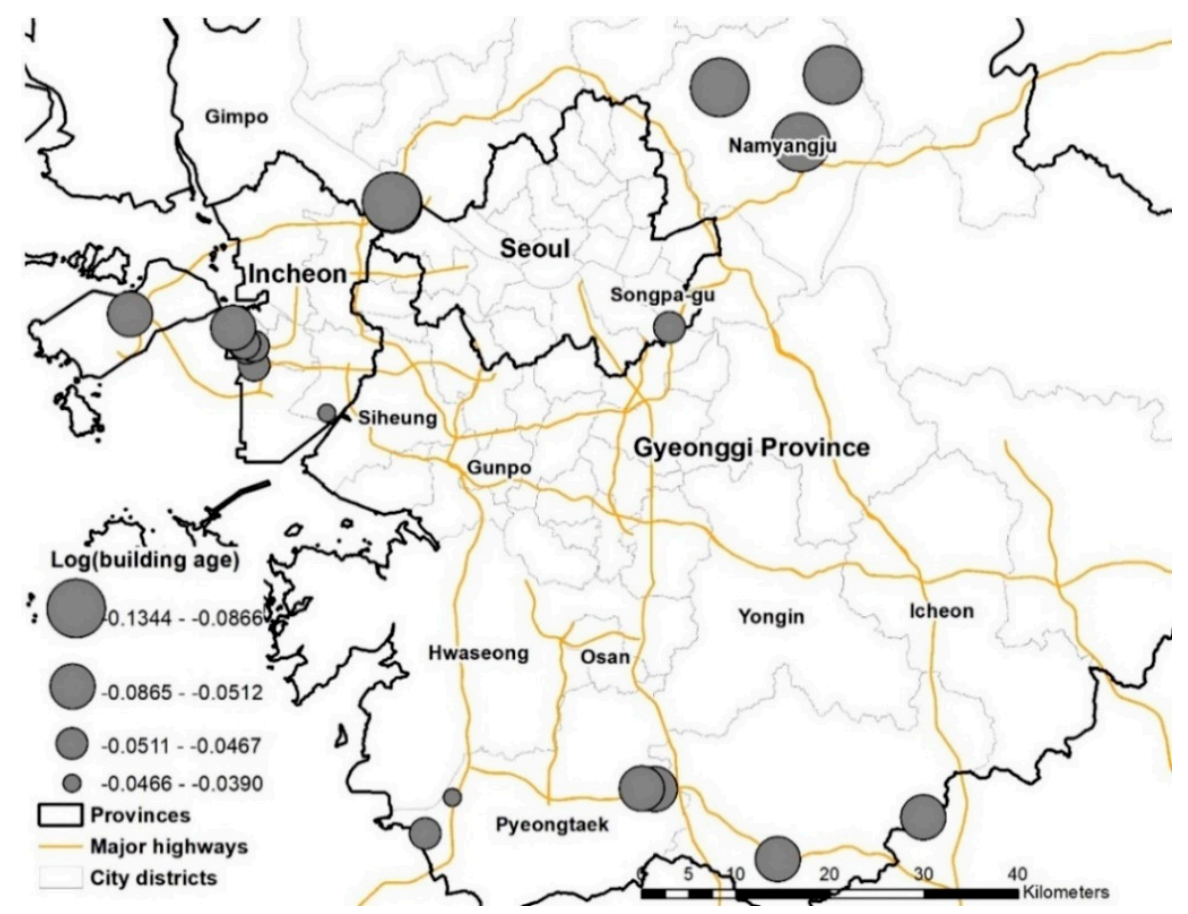

Figure 4. Spatial distribution of MGWR coefficients: Log of building age.

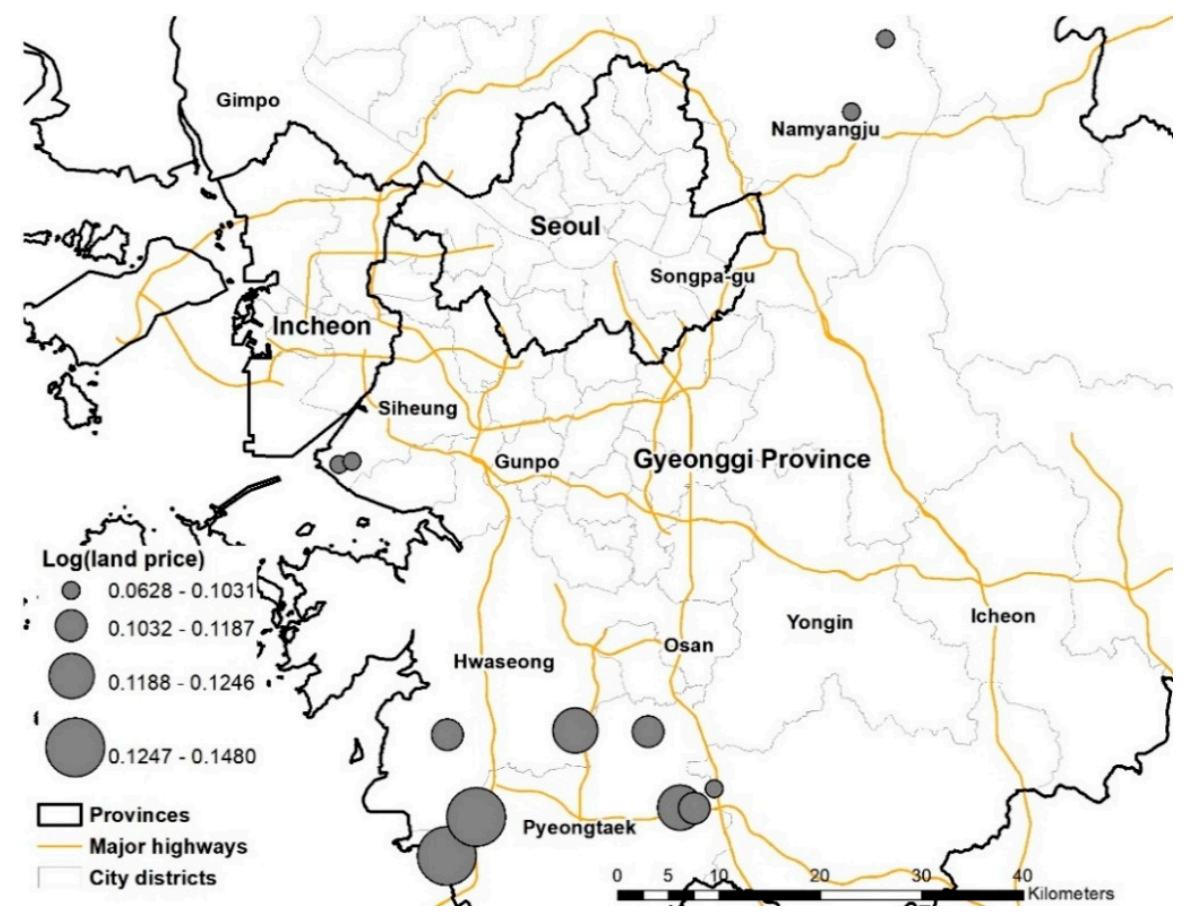

Figure 5. Spatial distribution of MGWR coefficients: Log of land price.

\section{Discussion}

This study examined the spatial stationary and non-stationary relationship between warehouse rent and its determinants based on the case of SMA in South Korea. According to the geographic variability test, distance to the nearest highway interchange, repackaging service, and built-in ramps were determined as global (fixed) variables. The positive effect of proximity to highway infrastructure on increasing rental prices was also reported in other previous studies on industrial property rents or values $[14,21]$. 
The presence of a built-in ramp had the largest effect on increasing warehouse rent among all the explanatory variables. According to the MGWR coefficient estimates, the presence of a built-in ramp in a warehouse is expected to increase the rental price by $22.7 \%$. Because of the consistent growth of the online shopping market in South Korea, demand for e-fulfillment warehouses close to densely populated urban areas has been increasing despite the high land price [31]. Therefore, most of the warehouses located near Seoul have been constructed as multi-story buildings to make maximum usage of the expensive land. Multi-story warehouses equipped with built-in ramps provide trucks with better access to upper-level floors making receiving and shipping operations more efficient than the conventional cargo elevators. Because of the higher construction cost, the rental price is expected to be much higher for the ramp-up warehouses.

Offering repackaging service had the second largest effect on increasing warehouse rent next to the presence of built-in ramps. The MGWR coefficient estimate suggests that offering repackaging service can increase warehouse rent by $10.3 \%$. Repackaging is a value-added service of changing the original manufacture's package into the company's own branded package or reconfiguring the products in any pre-assembled kits based on the customer's request. Repackaging has also become one of the essential services that e-fulfillment warehouses provide to consolidate multiple items from different vendors into a package for each online order.

The geographic variability test identified contract floor space, total building floor space, building age, and land price to be local (spatially varying) variables in the MGWR model. This is consistent with the previous studies on real estate properties showing that the relationship between real estate prices and property attributes is not invariant over space [38-40]. Such spatial variabilities of the regression coefficients reflect the unique characteristics of the local warehouse rental markets, ultimately revealing the spatial mismatch between the supply and demand of rental storage units in the SMA. For instance, the marginal effect of renting additional storage space on rental price increases was higher in warehouses close to Seoul especially in Songpa-gu of Seoul and Namyangju of Gyeonggi Province (Figure 2), possibly because of the shortage of storage space available for rent in such areas. However, such effect was much lower in Yongin of Gyeonggi Province where a relatively large number of rental warehouses are clustered indicating a possible oversupply of storage spaces.

The increase in rental prices for smaller warehouses was more severe in Namyangju because of the limited number of large warehouses in the area (Figure 3). The negative effect of building age on warehouse rent was more severe in northern Gyeonggi Province, such as Namyangju and Gimpo than the rest of the SMA (Figure 4). In fact, a mixture of warehouse buildings was found with large differences in building age and rent in the close vicinity, implying the presence of higher demand for newer warehouses in such areas. If a new warehouse cannot be built, the existing old warehouses can be renovated and upgraded to satisfy such needs. The positive effect of land price on warehouse rent was highest in the southwestern Gyeonggi Province especially in Pyeongtaek near the industrial complexes of manufacturing facilities indicating a high demand for storage spaces for the local manufacturing industry (Figure 5).

Our findings from the results have the following implications for the sustainable development of warehouses in the metropolitan area. Firstly, demand for new warehouses equipped with built-in ramps capable of providing repackaging services is high in locations close to urban centers in Seoul, especially for online retailers and convenience store suppliers providing fast delivery services. However, the supply of rental storage space is limited in such areas resulting in higher rental prices. Providing more warehouses with such capabilities close to the inner urban areas would contribute to sustainable urban logistics by significantly reducing the last-mile delivery distance. Gimpo and Namyangju can be desirable locations for establishing additional warehouses handling fast-moving consumer products considering their proximity to Seoul and relatively higher demand for new warehouses. If constructing a large warehouse is not feasible, local authorities can promote establishing small-sized fulfillment centers closely located to the end-customers in the urban centers allowing a mixture of commercial, residential, and logistics land use. One example would be renovating abandoned shopping centers or 
offices in the inner urban areas into e-fulfillment centers or online pickup or drop-off sites. Secondly, supplying additional large-sized warehouses can be promoted in major industrial complexes, especially in Pyeongtaek to support the growing semiconductor industry with the increasing trade with the Northeastern and Southeastern Asian countries through the Pyeongtaek Port. Thirdly, extreme caution is required when planning to establish additional warehouses in regions, such as Yongin where a possible oversupply of warehouse space is indicated.

\section{Conclusions}

This study investigated the spatial dimension of warehouse rent determinants identifying the regional specifics of supply and demand of warehouse facilities and services. This study provided hedonic pricing models that explain warehouse rent as a function of the transactional characteristics of the rental contracts, physical characteristics of the buildings, location factors, and various warehousing services based on the case of the SMA in South Korea. Two types of spatial autoregressive models (spatial lag and spatial error models) were applied to account for the spatial autocorrelation in the data set. Furthermore, MGWR model was used to examine the spatial stationary and non-stationary relationships between the rental price and its determinants. The MGWR results identified proximity to highway interchange, repackaging service, and built-in ramps as major needs of warehouse activities required by the customers to be applied across the entire study region. The MGWR results also identified contract floor space, total building floor space, building age, and land price as locally varying determinants of warehouse rent indicating the spatial mismatch of supply and demand of warehouse space in the SMA.

The results of this study allowed us to provide meaningful insights into the sustainable development of urban logistics facilities through a better understanding of the interaction between logistics activities, transportation infrastructure, and land use. Based on the results, we suggested the establishment of small-scale fulfillment centers handling fast-moving consumer goods near the inner urban areas through the mixture of commercial, residential, and logistics land use planning to mitigate the negative environmental impact of logistics sprawl. We also proposed that large-sized warehouses handling industrial products can be established away from the urban areas, but closely located to the major industrial complexes and seaports.

One of the limitations of this study is the limited number of samples in the data set. Unlike other types of real estate properties, details of warehouse rental transactions do not have to be reported to public authorities in South Korea. Therefore, warehouse rental transaction data are not available publicly, and it is extremely difficult to obtain such data. If more warehouse rental transaction records can be collected over multiple years, it would be possible to investigate the spatio-temporal dynamics of warehouse rent determination. The scope of this study was limited to the warehouse rental market in the SMA of South Korea. Therefore, our findings are unique to the case in the SMA, but the implications can be applied to other metropolitan areas with a similar urban environment. Furthermore, the current study is focused on regular warehouses handling dry goods. Future research can be conducted with analyzing the warehouse rent determinants by different commodity types, including refrigerated or frozen goods if additional data are collected.

Author Contributions: H.L. provided the core idea of this paper, analyzed the data, and wrote the manuscript. M.P. contributed to the conceptualization of this paper, data collection, and provision of valuable comments. All authors have read and agreed to the published version of the manuscript.

Funding: This research received no external funding.

Conflicts of Interest: The authors declare no conflict of interest. 


\section{References}

1. McKinnon, A. The present and future land requirements of logistical activities. Land Use Policy 2009, 26, S293-S301. [CrossRef]

2. Cidell, J. Distribution Centers among the Rooftops: The Global Logistics Network Meets the Suburban Spatial Imaginary. Int. J. Urban Reg. Res. 2011, 35, 832-851. [CrossRef]

3. Aljohani, K.; Thompson, R.G. Impacts of logistics sprawl on the urban environment and logistics: Taxonomy and review of literature. J. Transp. Geogr. 2016, 57, 255-263. [CrossRef]

4. Dablanc, L.; Rakotonarivo, D. The impacts of logistics sprawl: How does the location of parcel transport terminals affect the energy efficiency of goods' movements in Paris and what can we do about it? Procedia Soc. Behav. Sci. 2010, 2, 6087-6096. [CrossRef]

5. Wang, J.J.; Xiao, Z. Co-evolution between etailing and parcel express industry and its geographical imprints: The case of China. J. Transp. Geogr. 2015, 46, 20-34. [CrossRef]

6. Sakai, T.; Kawamura, K.; Hyodo, T. Logistics Facility Distribution in Tokyo Metropolitan Area: Experiences and Policy Lessons. Transp. Res. Procedia 2016, 12, 263-277. [CrossRef]

7. Dablanc, L.; Ogilvie, S.; Goodchild, A. Logistics Sprawl: Differential Warehousing Development Patterns in Los Angeles, California, and Seattle, Washington. Transp. Res. Rec. J. Transp. Res. Board 2014, 2410, 105-112. [CrossRef]

8. Sakai, T.; Kawamura, K.; Hyodo, T. Locational dynamics of logistics facilities: Evidence from Tokyo. J. Transp. Geogr. 2015, 46, 10-19. [CrossRef]

9. Giuliano, G.; Kang, S. Spatial dynamics of the logistics industry: Evidence from California. J. Transp. Geogr. 2018, 66, 248-258. [CrossRef]

10. Yuan, Q.; Zhu, J. Logistics sprawl in Chinese metropolises: Evidence from Wuhan. J. Transp. Geogr. 2019, 74, 242-252. [CrossRef]

11. Infosys; Korn Ferry; Penske; PennState. The 2019 23rd Annua Third-Party Logistics Study: The State of Logistics Outsourcing. Available online: http://www.3plstudy.com/3pl2019download.php (accessed on 12 October 2019).

12. Ballou, R.H. Business Logistics: Supply Chain Management, 5th ed.; Prentice Hall: Upper Saddle River, NJ, USA, 2003.

13. Ambrose, B. An Analysis of the Factors Affecting Light Industrial Property Valuation. J. Real Estate Res. 1990, 5, 355-370. [CrossRef]

14. Clark, D.; Pennington-Cross, A. Determinants of industrial property rents in the Chicago metropolitan area. Reg. Sci. Urban Econ. 2016, 56, 34-45. [CrossRef]

15. Löchl, M.; Axhausen, K. Modelling hedonic residential rents for land use and transport simulation while considering spatial effects. J. Transp. Land Use 2010, 3. [CrossRef]

16. Ibeas, Á.; Cordera, R.; dell'Olio, L.; Coppola, P.; Dominguez, A. Modelling transport and real-estate values interactions in urban systems. J. Transp. Geogr. 2012, 24, 370-382. [CrossRef]

17. Chen, Z.; Haynes, K.E. Impact of high speed rail on housing values: An observation from the Beijing-Shanghai line. J. Transp. Geogr. 2015, 43, 91-100. [CrossRef]

18. Goodman, A.C.; Thibodeau, T.G. The Spatial Proximity of Metropolitan Area Housing Submarkets. Real Estate Econ. 2007, 35, 209-232. [CrossRef]

19. Buttimer, R.; Rutherford, R.; President, R. Industrial Warehouse Rent Determinants in the Dallas/Fort Worth Area. J. Real Estate Res. 1997, 13, 47-55. [CrossRef]

20. Dunse, N.; Jones, C.; Brown, J.; Fraser, W.D. The spatial pattern of industrial rents and the role of distance. J. Prop. Invest. Financ. 2005, 23, 329-341. [CrossRef]

21. Beekmans, J.; Beckers, P.; van der Krabben, E.; Martens, K. A hedonic price analysis of the value of industrial sites. J. Prop. Res. 2014, 31, 108-130. [CrossRef]

22. Anselin, L.; Getis, A. Spatial statistical analysis and geographic information systems. Ann. Reg. Sci. 1992, 26, 19-33. [CrossRef]

23. Anselin, L. Spatial Econometrics: Methods and Models; Springer: Dordrecht, The Netherlands, 1988.

24. Lan, F.; Wu, Q.; Zhou, T.; Da, H. Spatial Effects of Public Service Facilities Accessibility on Housing Prices: A Case Study of Xi'an, China. Sustainability 2018, 10, 4503. [CrossRef] 
25. Alonso, W. Location and Land Use: Toward a General Theory of Land Rent; Harvard University Press: Cambridge, UK, 1964.

26. Rosen, S. Hedonic prices and implicit markets: Product differentiation in pure competition. J. Political Econ. 1974, 82, 34-55. [CrossRef]

27. Helbich, M.; Brunauer, W.; Vaz, E.; Nijkamp, P. Spatial Heterogeneity in Hedonic House Price Models: The Case of Austria. Urban Stud. 2014, 51, 390-411. [CrossRef]

28. Malpezzi, S. Hedonic pricing models: A selective and applied review. In Housing Economics and Public Policy; O'Sullivan, T., Gibb, K., Eds.; Blackwell: Oxford, UK, 2003; pp. 67-89.

29. Wu, H.; Jiao, H.; Yu, Y.; Li, Z.; Peng, Z.; Liu, L.; Zeng, Z. Influence Factors and Regression Model of Urban Housing Prices Based on Internet Open Access Data. Sustainability 2018, 10, 1676. [CrossRef]

30. Yu, D. Modeling Owner-Occupied Single-Family House Values in the City of Milwaukee: A Geographically Weighted Regression Approach. GIScience Remote Sens. 2007, 44, 267-282. [CrossRef]

31. Lim, H.; Yoo, E.H.; Park, M. Warehouse rental market segmentation using spatial profile regression. J. Transp. Geogr. 2018, 73, 64-74. [CrossRef]

32. Yang, N. A Study on Determintns for Storage Fee of Logistics Facilities in Seoul Metropolitan Area. Master's Thesis, INHA University, Incheon, Korea, February 2016.

33. Brunsdon, C.; Fotheringham, A.S.; Charlton, M.E. Geographically Weighted Regression: A Method for Exploring Spatial Nonstationarity. Geogr. Anal. 1996, 28, 281-298. [CrossRef]

34. Fotheringham, S.A.; Brunsdon, C.; Charlton, M. Geographically Weighted Regression: The Analysis of Spatially Varying Relationships; Wiley: Chichester, UK, 2002.

35. Wheeler, D.; Tiefelsdorf, M. Multicollinearity and correlation among local regression coefficients in geographically weighted regression. J. Geogr. Syst. 2005, 7, 161-187. [CrossRef]

36. Brunsdon, C.; Fotheringham, A.S.; Charlton, M. Some Notes on Parametric Significance Tests for Geographically Weighted Regression. J. Reg. Sci. 1999, 39, 497-524. [CrossRef]

37. Nakaya, T.; Fotheringham, A.S.; Brunsdon, C.; Charlton, M. Geographically weighted Poisson regression for disease association mapping. Stat. Med. 2005, 24, 2695-2717. [CrossRef]

38. Bitter, C.; Mulligan, G.F.; Dall'erba, S. Incorporating spatial variation in housing attribute prices: A comparison of geographically weighted regression and the spatial expansion method. J. Geogr. Syst. 2007, 9, 7-27. [CrossRef]

39. Osland, L. An Application of Spatial Econometrics in Relation to Hedonic House Price Modeling. J. Real Estate Res. 2010, 32, 289-320. [CrossRef]

40. Yu, D.; Wei, Y.D.; Wu, C. Modeling Spatial Dimensions of Housing Prices in Milwaukee, WI. Environ. Plan. B Plan. Des. 2007, 34, 1085-1102. [CrossRef]

(C) 2019 by the authors. Licensee MDPI, Basel, Switzerland. This article is an open access article distributed under the terms and conditions of the Creative Commons Attribution (CC BY) license (http://creativecommons.org/licenses/by/4.0/). 